\title{
Problems in University Teaching Faculty Construction and Countermeasures
}

\author{
Yuzheng $\operatorname{Han}^{1}$ \\ ${ }^{1}$ Personnel Division, Changchun University of Science and Technology, China \\ Correspondence: Yuzheng Han, Personnel Division, Changchun University of Science and Technology, China
}

Received: November 2, 2015

Accepted: November 12, 2015

Online Published: November 16, 2015

doi:10.5430/ijhe.v4n4p239

URL: http://dx.doi.org/10.5430/ijhe.v4n4p239

\begin{abstract}
The construction of university teaching faculty directly affects and restricts the long-term development of universities. Since the reform and opening up, China's university teaching faculty construction has realized marvelous achievements. However, in comparison with the higher education in developed countries, in China the construction of university teaching faculty still faces quite a lot problems needed to be solved. In this paper, the author systematically analyzes the current situations of China's university teaching faculty construction, as well as the problems, and puts forward suggestions for how to optimize university teaching faculty construction and how to improve the overall level of university teaching faculty.
\end{abstract}

Keywords: College, Teaching faculty construction, Problems, Countermeasures

\section{Introduction}

Today with the globalization sweeping the world and the international situation experiencing great changes, world higher education has undergone significant reforms. At the new normal times, China's university teaching faculty construction also faces new opportunities and challenges, especially the proposal of strengthening higher education strategy and building world-class universities, which sets higher demands for university teaching faculty construction. To strengthen university teaching faculty construction, optimize the teaching faculty structure, and improve the quality and efficiency of teaching faculty has become the vice of the age (Sun, Defen, 2012). In order to build a stronger country of higher education on the basis of a giant country of higher education, we should focus on the teaching quality and emphasize on the key status of teaching faculty, confirming the ideology of "teachers are the primary resources" and establishing a high-quality and skillful teaching faculty. High-quality teachers ensure better teaching. Therefore, to clearly understand the situations and problems in China's university teaching faculty construction, adopt effective measures to optimize the construction, and improve the general level of teaching is an important task facing the country.

\section{The status of China's university teaching faculty construction and the main issues}

For a long time, the Chinese government has always attached great importance to the construction of university teaching faculty and has released a series of policies and regulations to promote the construction. However, there is still a large gap between the quality of China's university teaching faculty and that of world-class universities'. The shortage of top talents has become a bottleneck restricting the development of China's higher education (Yu, Shanyun, 2012). Starting from the hot issues of China's university teaching faculty construction and understanding its status and main issues has become the common tasks of all Chinese universities at present. We must pay attention to these issues in future reform and development.

\subsection{The teaching faculty continues to be optimized, but still struggles with shortage and imbalance of structure}

Since the reform and opening up, China's higher education has made leaps and bounds, achieving the transformation from "elite education" to "mass education". With the continuous enlargement of higher education, the size of university teaching faculty grows constantly, realizing a stable rise of total amount. By the end of 2014, the size of teaching faculty in colleges and universities reached 2.3357 million, representing an increase of $1.72 \%$ over the same period last year. The ratio of teachers to students is 1:17.68 (Ministry of Education of People's Republic of China, 2014). In recent years, teachers in colleges and universities have realized a substantial increase in educational levels. Nearly $80 \%$ teachers have obtained the Doctor degree or master degree accounted. Otherwise, the proportion of high-level teachers, such as professors and associate professors, is relatively lower (Table 1), only 41.01\%. As for the 
age distribution, it tends to be younger. Middle-age and young teachers (under the age of 40) occupy a large proportion $(57.85 \%)$. The proportion of teachers above 40 -year-old with senior titles is relatively lower.

Meanwhile, the construction of university teaching faculty still faces serious shortage and structural problems. The first is the issue of inadequate positions. In recent years, the continuous expansion of higher education enrollment causes a serious shortage of teachers. Unfortunately, due to the prominent contradiction between higher education demand and financial supply, it is impossible for universities and colleges recruiting adequate teachers at once. They have to take supplements of teachers step by step, resulting in the inadequacy of teachers in general (Lin, Xiaoyan \& Luo, Xiongrong, 2010). Secondly, the structural optimization of university teaching faculty lags behind the higher education needs. Although most universities and colleges has taken measures to optimize the teaching faculty, it still lacks scientific planning, which results in a lower process or a blind adjustment. A case in point is the imbalanced proportion of basics teachers and specialty teachers. Recently, universities and colleges have adjusted the specialty arrangement and enrollment size based on the employment market. As a result, some popular majors seem to be short for the demand, which drives further expansion of enrollment. Consequently, specialty teachers are in serious short. In order to take in teachers as soon as possible, universities and colleges may ignore the professional requirements, resulting in the lack of good teachers.

Table 1. Overview of ages and professional titles of university teachers in 2014. (unit: \%)

\begin{tabular}{lllllllllll}
\hline & Under 30 & $30-34$ & $35-39$ & $40-44$ & $45-49$ & $50-54$ & $55-59$ & $60-64$ & Above 65 & Total \\
\hline Professor & 0.03 & 0.72 & 4.54 & 14.92 & 30.33 & 24.05 & 17.17 & 4.98 & 3.27 & 12.13 \\
Associate professor & 0.29 & 7.17 & 20.81 & 25.91 & 23.31 & 13.31 & 6.74 & 1.49 & 0.97 & 28.88 \\
Lecturer & 10.56 & 42.10 & 25.06 & 12.00 & 5.96 & 2.84 & 1.21 & 0.21 & 0.06 & 39.88 \\
Assistant lecturer & 56.22 & 31.45 & 7.17 & 2.74 & 1.32 & 0.71 & 0.36 & 0.02 & 0 & 13.61 \\
Unsettled title & 69.74 & 18.97 & 4.78 & 2.26 & 1.32 & 0.86 & 0.77 & 0.17 & 0.04 & 5.50 \\
Total & 15.79 & 24.27 & 17.79 & 14.57 & 13.04 & 8.04 & 4.60 & 1.13 & 0.70 & 15.79 \\
\hline
\end{tabular}

Source: Department of development and planning, Ministry of Education of People's Republic of China: China Education Statistical Yearbook 2014.

\subsection{World-class masters, top elites and leading talents are in extreme short}

China has the world's largest size of university teaching faculty, but lacks of world-class masters (Lin, Xiaoyan \& Luo, Xiongrong, 2014). In recent years, universities and colleges have implemented the talent-oriented strategy and introduced a large batch of high-level teachers. However, there is still a serious shortage of top elites and leading talents. The structure of university teaching faculty faces the following five issues: first, there are too many basics teachers but few high-level specialty teachers; second, too many teachers for traditional majors but few for high-tech and new majors; third, too many conservative teachers but few creative ones; fourth, too many academic teachers but few practical and industrial teachers; fifth, too many one-specialty teachers but few cross-disciplinary teachers (Zhang, Dichen, 2015).

In China, the academicians (Chinese Academy of Sciences, Chinese Academy of Engineering) and the chief scientists of "973" Program are representatives of the highest level of scientific research. Some of them are academic masters and scientific and technological leaders in universities and colleges. Currently, more than $40 \%$ academicians are from universities and colleges where more and more academicians have grown from. In 2015, among the 157 candidates for Chinese Academy of Sciences, 94 are from universities and colleges. The total number seems high. However, in perspective of the distribution of academicians, there are only few universities with more than 20 academicians. Besides, most academicians work for universities in the " 985 " and " 211 " programs. Quite a lot of university only has less than ten academicians. The shortage of top talents is common in most universities and colleges. Therefore, it is not easy to develop efficient professional teams for creative studies in universities and colleges. As a result, there is lack of high-level scientific fruits, which makes it more difficult to improve the general level of higher education of China.

\subsection{Lack of leading young and middle-aged scientists and the internationalization of university teachers need to be improved}

In the process of building top-level and specialized higher educational institutions, the most essential foundation is the high-level young and middle-aged scientists. To cultivate qualified young and middle- aged academic backbone 
and optimize the structure of scientific research teams are important ways for universities and colleges improving their comprehensive powers and teaching qualities. A survey shows that many domestic universities and colleges are confronted with problems in the construction of young and middle-aged academic scientists. A case in point is the Youngster River Scholars and winners of outstanding youth funds. In 2008, 1559 Youngster River Scholars have been employed in 126 universities, in which only 2 universities have more than one hundred Youngster River Scholars and guest professors, 7 universities more than 50, and 85 universities less than 10. As for the distribution of winners of outstanding youth funds, 1372 winners work in 115 universities and colleges, in which only 2 universities have more than one hundred winners, 6 universities more than 50 winners, and most universities less than 10 (Xu, Anguo \& Zhao, Qingxian, 2010). Apparently, it is common for universities and colleges in serious shortage of high-level young and middle-aged scientists, which may exert negative effects on some cross- disciplinary and new specialties.

In addition, the quality of university teachers needs to be improved at an international level. During recent years, in order to improve the teaching and comprehensive level and quality education, universities and colleges follow the idea of "learning outside and working inside" and make great effort on introducing foreign scholars. For instance, enhance the cooperation and communication with foreign experts and universities, and encourage qualified young and middle-aged scientists to further education oversea. Generally speaking, the university teaching faculty is still far from reaching an international level. Most university teachers have no background of international education (Peng, Hua, 2013). Besides, due to the limitation of languages, academic levels, and study periods, the "leaning outside" teachers may find it hard to develop in-depth and essential cooperation with foreign top-level scientists. Therefore, the oversea study experience may not benefit a lot as expected.

\subsection{The mechanism in favor of outstanding talents needs to be improved}

At present, some universities and colleges continue to explore and reform the teaching faculty management mode, in the hope of creating a new mechanism and approach to catch up with the world. However, the "soft environment" for university teaching faculty construction is confronted a series of problems as follow.

First of all, the performance evaluations, promotions, incentives and many other equipped systems lag behind seriously. Performance evaluations and incentives are important parts of modern human resource management. Only scientific and reasonable performance evaluations and incentives can help to stimulate the potentials of people. However, many universities and colleges still have no scientific performance evaluation system. The annual evaluations just cover the traditional five aspects, i.e. morals, abilities, diligence, grades, integrities, which is neither scientific nor objective. Meanwhile, the promotion system is imperfect, in which the unified quantitative standard terribly ruins the initiatives of some teachers.

Secondly, some academic organizations are not right for the formation and development of competitive teams due to the lower creative level. As a matter of fact, China's academic organizations are based on learning from Soviet pattern. The "college-department-study room" structure reflects the characteristic of knowledge orientation, which had its moment in certain historical time. However, with the fast development of higher education, this structure is inappropriate for knowledge production, dissemination, and application, blocking the integration of different disciplines and the cross- disciplinary development.

\section{Countermeasures for the construction of China's university teaching faculty}

To strengthen the university teaching faculty construction is a long-term complicated systematic project, as well as a strategic and general mission. For universities and colleges, it is necessary to establish the ideology of "talents are the primary resources" and make up effective measures on the basis of general and individual conditions. Only by developing a long-term system for the construction of university teaching faculty, can it settle down these problems mentioned above, improve the general level of teaching faculty, and contribute to the continuous development of higher education.

\subsection{Seize the opportunity of "Thousands of Talents" program and introduce more high-end talents in urgent need}

Universities and colleges should take full advantage of the opportunity of the state implementing the talent projects and try their best to introduce more world-class scientists, academic leaders, and young elites into their fields, especially for the critical disciplines and strategic newly-developed disciplines. On one hand, make best use of the platforms of "Thousands of Talents", "Yangtze River Scholars", and "Hundreds of Talents" and improve the inner mechanism of introducing and utilizing foreign high-end scholars. It is better to have some full-time leading scholars. On the other hand, make sure the talents integration effect of universities and colleges through alumni and visiting scholars. Take initiatives to acquire new resources, first-class knowledge, thoughts, academic masters, and scientific 
leaders (Li, Ying \& Sun, Jianpeng, 2013). Besides, create a favorable environment for the introduction of talents, support the team work, and help them overcome national critical engineering projects. By this way, we can build a wide space for the growth of high-end talents.

\subsection{Establish a supporting system for training talents}

The development of the state is based on people, while people need to be cultivated through education. Higher education, as the senior stage of education, takes the cultivation of talents as its primary task. The quality of education is under the restriction of many other factors, in which the key is the competence of teaching faculty. In fact, the teaching faculty is the foundation of education. An indisputable fact is that one university's operational characteristics, academic level, and quality of cultivation depend on a condition of whether there is first-class teaching faculty.

Universities and colleges should make constant innovations and improve personnel policies based on individual conditions. Emphasize on the introduction of leading talents, as well as the internal training for current teachers. Design training programs especially for the young and middle-aged teachers and help to grow in academic field and teaching platform. Improve the overall level of teaching faculty in academics and teaching. Establish an efficient and mature system for introducing and training teachers ( $\mathrm{Zhou}, \mathrm{Li}, 2012$ ). The mode in Figure 1shows the training program for special industry in certain university in Beijing. This university optimizes its disciplinary arrangement based on social demand. By taking advantage of internal and external resources, the university conducts continuous explorations and makes constant innovations, resulting in building a new mode for training teachers for special industry. In this mode, it divides the training into three parts, i.e. industrial recognition, industrial practice, and industrial service. Implement the module training and achieve the comprehensive, multi-channel, and wide-range teacher-training mode. By this way, it properly solves the problem of insufficient teachers for special industry. This mode proves to be a suacace

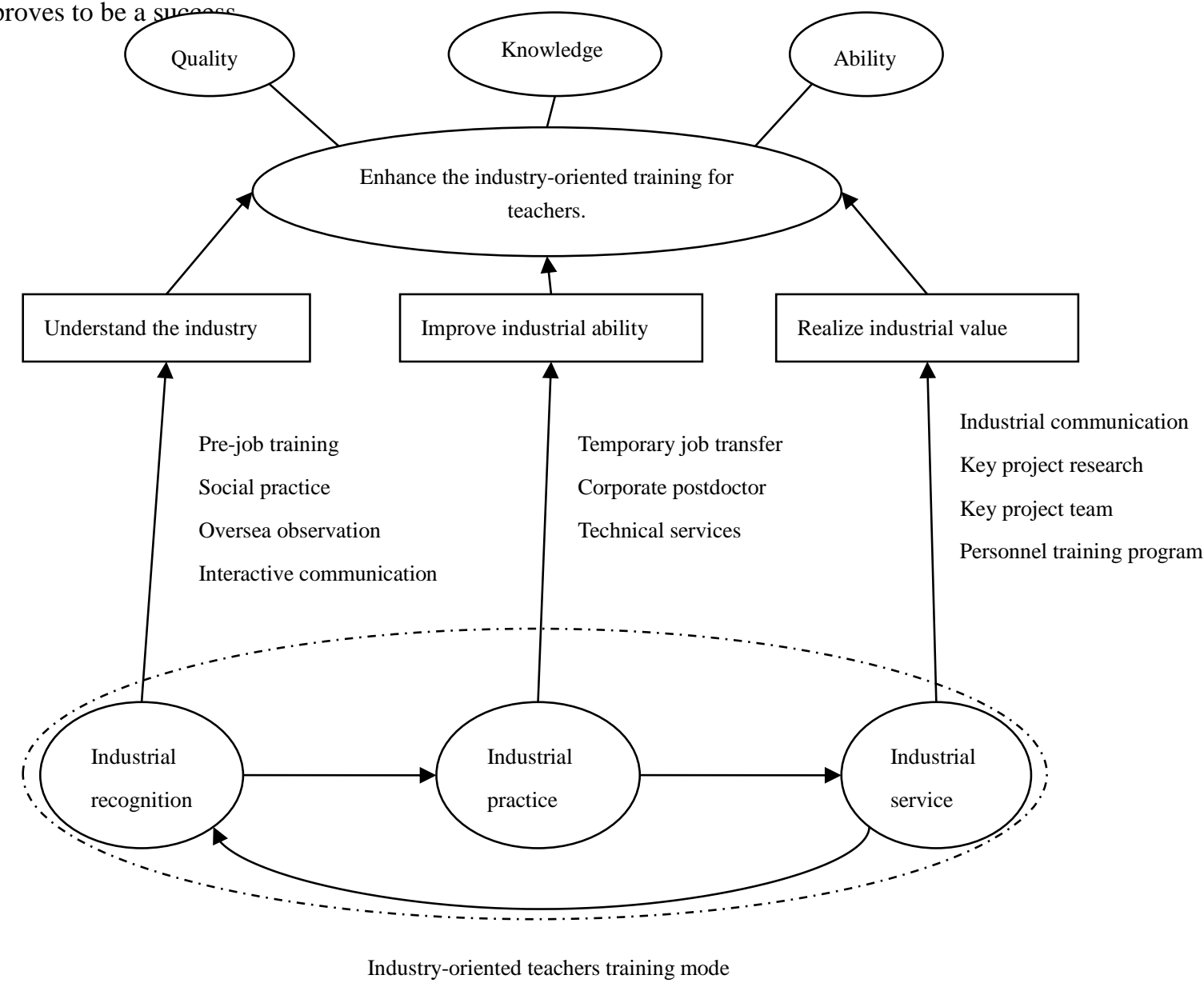

Figure 1. The training mode for industry-oriented teachers 
3.3 Use the international personnel development pattern and improve the international competitiveness of university teaching faculty

Universities and colleges should build a big picture of talents construction and develop a long-term development pattern through focusing on improving the international competitiveness of university teaching faculty, modifying the existing personnel mechanism and environment, and reshaping the talents training mode. On one hand, universities and colleges should further regulate and enhance the introduction of foreign elites, and ensure the quality of imported talents. On the other hand, they should continue to improve the talents training mechanism and establish a high-level oversea learning mechanism. For instance, provide English training for teachers who are intended to study oversea. Help more and more young and middle-aged ambitious teachers to pursue for in-depth study outside and make sure that they have the chance of communicating with world-class scientists in their fields. By this way, improve the academic and teaching level of university teachers. Besides, universities and colleges can invite world masters and leading scientists to give lectures, which also prove to be a good opportunity for teachers to benefit.

\subsection{Focus on establish relevant systems and create a soft environment in favor of the growth of talents}

People are the product of environment. The growth of talents depends on a favorable environment. To build an appropriate "soft environment" is critical for the growth of university teachers. Here, the key and the urgent is the construction of relevant systems.

As for the human personnel system, universities and colleges should stimulate teachers' initiatives and creativity and try to overcome the difficulties of restricting people's development. Adhere to the principle of "arrange positions for needs, open recruitment, fair competition, and contracted management" and improve the selection mechanism on the basis of enhancing and improving the top design. Besides, the system should be designed according to the practical needs of discipline, combining the construction of university teaching faculty and position arrangement. Establish the new teacher management system and achieve the efficiency of teacher selection, performance evaluation, title promotion, distribution and incentives.

As for the performance evaluation, it is better to establish a unified modern assessment system which consists of employment evaluation, promotion evaluation, and performance evaluation. Here, the employment evaluation should be taken as the main indicator reflecting the potential of a teacher. The promotion evaluation should be based on the teacher's academic level and contributions. The performance evaluation should focus on the teacher's teaching effect and relevant performances. It is necessary to make further explanation on how to classify the indicators, how to establish the classification standards, and how to achieve a quantitative evaluation.

As for the salary distribution and incentive compensation, universities and colleges should further improve the incentive system to connect the performance and the compensation. Adhere to the distribution principle of "more returns for more work, better compensations for better performance, allow reasonable distances". Carry out the "people-oriented and goodness-oriented" idea and reform the current "person-based salary" into "position-based salary". Realize the policy of salary changing along with positions. Meanwhile, try to achieve an effective association of compensations and incentives and reflect the reasonable differences of salaries (Xu, Xiaojun, 2014).

As for the construction of academic organizations and creative teams, universities and colleges should actively learn from the practices and experiences in Europe and America. Help the primary academic organizations to expand the academic field and set up various primary academic organizations. Meanwhile, empower the primary academic organizations and their leading scholars with sufficient academic powers and ensure that they can make independent decisions in the field of academic studies. Besides, help to establish creative academic teams and promote to improve the academic level of these teams.

\section{Conclusion}

Since the reform and opening up, China's higher education has achieved great progresses. So does the university teaching faculty construction, with increasing size, optimized structure, and improved quality, which serves as solid foundation for the harmonious development of national higher education. However, in China the university teaching faculty construction is still confronted with many problems, which may block the in-depth development of higher education. Therefore, universities and colleges should always focus on the construction of teaching faculty in order to ensure the long lasting development. They must take individual conditions into consideration, adhere to the scientific concept of development, and fully implement the talent strategy. Furthermore, universities and colleges must improve the talents introduction system and create favorable environment for the growth of talents. By this way, they may possess a team of teachers with both academic abilities and teaching skills. 


\section{References}

Li, Ying \& Sun, Jianpeng. (2013). Strategic human resource management and the construction of university faculty exploration. Science-Technology and management, $\quad$ No.15(2): http://dx.doi.org/10.3969/j.issn.1008-7133.2013.02.027

Lin, Xiaoyan \& Luo, Xiongrong. (2010). The construction of Chinese college teaching faculty: situations, problems, and countermeasures. Theory Monthly, No.12: 183-185. http://dx.doi.org/10.3969/j.issn.1004-0544.2010.12.052

Ministry of Education of People's Republic of China. (2014). National Educational Development Statistical Report 2014 , July $30^{\text {th }}$.

Peng, Hua. (2013). University teaching faculty construction and management: problems and countermeasures. Education and Vocation, No.20: 58-60. http://dx.doi.org/10.3969/j.issn.1004-3985.2013.20. 025

Sun, Defen. (2012). Building a mechanism for the internationalization of university teaching faculty construction. Education Review, No.3:42-44.

$\mathrm{Xu}$, Anguo \& Zhao, Qingxian. (2010). An analysis on and countermeasures for the construction of teaching staff in colleges and universities. Journal of Beijing Jiaotong University (Social Sciences Edition), No.2: 106-109, 128. http://dx.doi.org/10.3969/j.issn.1672-8106.2010.02.021

$\mathrm{Xu}$, Xiaojun. (2014). Reform China's university teachers' salary system by referencing to foreign university teachers' salary conditions. Market Forum, No.2: 52-54. http://dx.doi.org/10.3969/j.issn.1672-8777. 2014.02.018

Yu, Shanyun. (2012). Discipline and teaching staff construction of open university in China. Education Research, No.2: 47-53. http://dx.doi.org/10.3969/j.issn.1007-2179.2012.02.008

Zhang, Dichen. (2014). The American university teaching faculty management institution and the enlightenment for China. Education and Vocation, No.2: 73-75. http://dx.doi.org/10.3969/j.issn.1004-3985.2014. 02.031

Zhou, Li. (2012). Application of theory of university teachers' development in China's university teaching faculty construction. Journal of Southern Review, $\quad$ No.2: http://dx.doi.org/10.3969/j.issn.1004-1133.2012.02.040 